\title{
Reactor for in situ measurements of spatially resolved kinetic data in heterogeneous catalysis
}

\author{
R. Horn, O. Korup, M. Geske, U. Zavyalova, I. Oprea, R. Schlögl \\ Fritz-Haber-Institut der Max-Planck-Gesellschaft, Departement of Inorganic Chemistry, D-14195 Berlin, Germany
}

Received 19 January 2010; accepted 20 April 2010; published online 8 June 2010

\begin{abstract}
The present work describes a reactor that allows in situ measurements of spatially resolved kinetic data in heterogeneous catalysis. The reactor design allows measurements up to temperatures of $1300^{\circ} \mathrm{C}$ and 45 bar pressure, i.e., conditions of industrial relevance. The reactor involves reactants flowing through a solid catalyst bed containing a sampling capillary with a side sampling orifice through which a small fraction of the reacting fluid (gas or liquid) is transferred into an analytical device (e.g., mass spectrometer, gas chromatograph, high pressure liquid chromatograph) for quantitative analysis. The sampling capillary can be moved with $\mu \mathrm{m}$ resolution in or against flow direction to measure species profiles through the catalyst bed. Rotation of the sampling capillary allows averaging over several scan lines. The position of the sampling orifice is such that the capillary channel through the catalyst bed remains always occupied by the capillary preventing flow disturbance and fluid bypassing. The second function of the sampling capillary is to provide a well which can accommodate temperature probes such as a thermocouple or a pyrometer fiber. If a thermocouple is inserted in the sampling capillary and aligned with the sampling orifice fluid temperature profiles can be measured. A pyrometer fiber can be used to measure the temperature profile of the solid catalyst bed. Spatial profile measurements are demonstrated for methane oxidation on $\mathrm{Pt}$ and methane oxidative coupling on $\mathrm{Li} / \mathrm{MgO}$, both catalysts supported on reticulated $\alpha-\mathrm{Al}_{2} \mathrm{O}_{3}$ foam supports.
\end{abstract}

Keywords: catalysis, catalysts, chemical reactors, fluidised beds, pyrometers, reaction kinetics, thermocouples

\section{Introduction}

Reactor measurements are central to heterogeneous catalysis research and sophisticated reactor designs have been developed, e.g., for kinetic measurements [1] and high throughput screening.[2] However, apart from reactors which feature a number of discrete sampling points (typically less than ten), most reactor designs have in common that reaction products are analyzed in the reactor effluent stream be it gaseous or liquid. The reaction pathway, i.e., how the reactants are transformed into the products remains hidden and only a single kinetic data point is obtained for a set of reaction variables. Furthermore, heterogeneous catalysts are dynamic systems that adapt to the chemical potential of the surrounding fluid phase, which in turn is determined by the composition of the fluid phase, its temperature, and pressure. Consequently, if a heterogeneous catalytic reaction is studied under temperature and pressure conditions conveniently manageable in a laboratory reactor it is always questionable whether the obtained data and any derived kinetic model can be extrapolated to industrially relevant conditions.

The reactor described in this work allows simultaneous measurements of spatially resolved species and temperature profiles at temperatures up to about $1300^{\circ} \mathrm{C}$ and pressures up to 45 bar. If mass transport limitations can be excluded, differential reaction rates can be directly calculated from the species profiles and correlated with composition and temperature values at the respective point in the catalyst bed. If transport limitations are inevitably connected to the reaction conditions, numerical simulations can be used to validate microkinetic models by means of spatial species data.[3] Errors introduced by an incorrect heat balance can be avoided by using the measured temperature profile as input. 


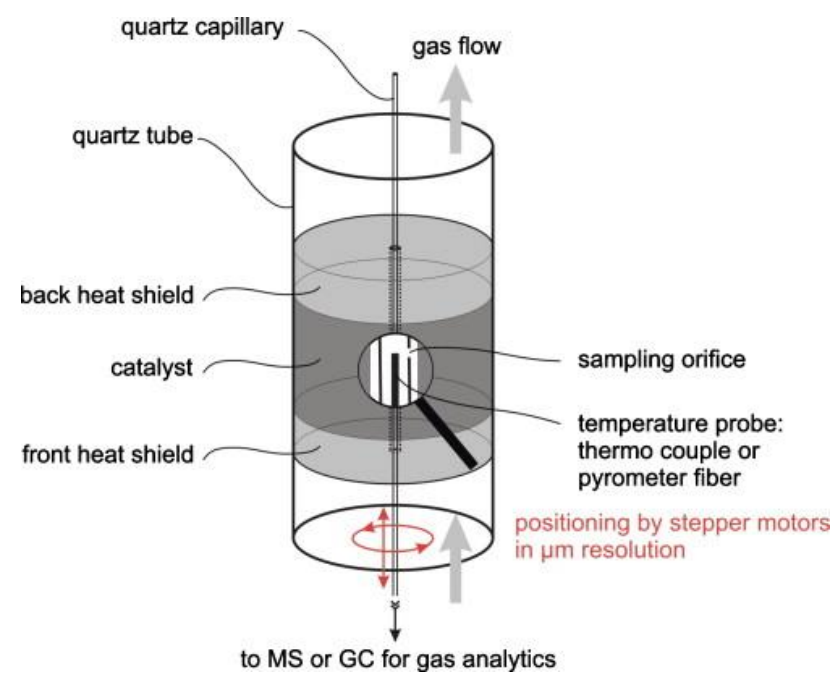

Fig. 1: Principle of spatially resolved measurement of (i) kinetic data, (ii) gas temperature, and (iii) solid temperature.

In contrast to early reactor designs by Horn et al. $[4,5,6]$ for atmospheric pressure measurements, the novel reactor presented in this work can be safely operated up to 45 bar pressure and is much more flexible in terms of scan range and exchangeability of the catalyst bed. However, the measurement principle as depicted in Fig. 1 is the same as in the earlier works.[4,5,6]

The catalytic reaction is conducted in a flow reactor containing the catalyst bed sandwiched between two inert packings to check in each experiment for activity of the support as well as precatalytic and postcatalytic chemistry. The inert packings also limit heat losses by radiation and are therefore called heat shields. As the gas flow is typically arranged from bottom to top, the stack sequence in flow direction is front heat shield, catalyst, back heat shield (cp. Fig. 1). Profiles of reactants, intermediates, and products are measured by moving a thin sampling capillary with $\mu \mathrm{m}$ resolution through the centerline of the catalyst bed. Sampling occurs via a side sampling orifice drilled at such a distance from the closed capillary tip that no open channel results from moving the capillary up and down. The catalyst bed can be of various shape. Reticulated foams, sphere beds, and catalyst coated channels have been measured successfully up to a total length of $120 \mathrm{~mm}$. In addition to species sampling the capillary can accommodate a thermocouple to measure the gas temperature or a pyrometer fiber to measure the temperature of the catalyst. The application examples presented in this work stem from the field of high temperature gas phase oxidation catalysis. After a detailed description of the reactor design in Sec. 2, spatially resolved measurements for methane oxidation on $\mathrm{Pt}$ and $\mathrm{Li} / \mathrm{MgO}$ coated reticulated foam supports are presented and briefly discussed.

\section{Reactor design}

\subsection{Reactor body}

An annotated three dimensional drawing of the reactor is shown in Fig. 2. The quartz reactor tube is $200 \mathrm{~mm}$ long, has an inner diameter of $18 \mathrm{~mm}$ and an outer diameter of $38 \mathrm{~mm}$ (wall thickness $10 \mathrm{~mm}$ ). Both ends of the reactor tube containing the catalyst bed are conically shaped. For pressure sealing of the reactor tube, the cone faces are greased with laboratory silicone grease and form fit tightly into a lower and an upper water cooled copper clamp. The lower copper clamp is mounted to a stainless steel flange which in turn is mounted to a fixed aluminum base plate. The upper copper clamp is mounted to a movable cover plate also made of aluminum. As high axial but no lateral force must be applied to the quartz tube, a precise vertical movement of the upper mounting clamp is required. This is accomplished by four linear bearings mounted between cover and base plate allowing for precise vertical movements of up to $110 \mathrm{~mm}$. For exchange of the reactor tube, the upper cover plate can be lifted and lowered easily by means of a hydraulic jack. If the reactor is closed and pressurized, springs (not shown in Fig. 2) hinged on hooks between base and cover plate keep the quartz tube pressure sealed. The entire reactor stands on four legs with bases.

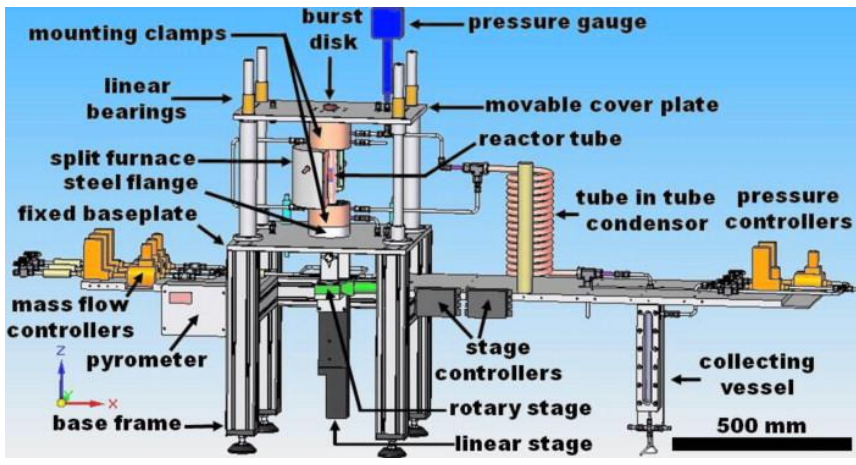

Fig. 2: Annotated 3D reactor drawing.

\subsection{Gas flow control, pressure control, heater, and safety}

The gas flow through the reactor setup is arranged from left to right and through the reactor tube from bottom to top. At the inlet side, three gas pipes are connected to mass flow controllers. In oxidation catalysis the feed gas is typically composed of an oxidant $\mathrm{O}_{2}, \mathrm{~N}_{2} \mathrm{O}$..., a hydrocarbon $\left(\mathrm{CH}_{4}, \mathrm{C}_{2} \mathrm{H}_{6}, \mathrm{C}_{3} \mathrm{H}_{8} \ldots\right)$ and an inert standard $\left(\mathrm{Ar}, \mathrm{He}, \mathrm{N}_{2} \ldots\right)$. Therefore three gases can be mixed using this gas supply. The feed gas mixture enters the reactor tube from the bottom, flows through the catalyst bed, and leaves at the top. After leaving at the top, the reactor effluent gases pass through a tube in tube heat exchanger to remove all condensable species which are collected in a reservoir. The 
reservoir can be emptied under operation without pressure loss by means of a needle valve. The dry reactor effluent passes through pressure controllers which expand it to atmospheric pressure. Three exit lines can be chosen, one for operation at atmospheric pressure, the second for operation at pressures between 1 and 7 bar, and the third for pressures between 7 and 45 bar. For precise pressure measurement in the reactor, a digital pressure gauge is connected close to the reactor tube outlet.

To heat the catalyst, the quartz reactor tube is surrounded by a split furnace $(450 \mathrm{~W}$, maximum element temperature $1150^{\circ} \mathrm{C}$ ) connected to a power supply and a temperature controller. The heat transfer between heater and catalyst bed occurs primarily via radiation resulting in a maximum temperature of about $1000^{\circ} \mathrm{C}$ inside the reactor tube without accounting for any heat of reaction. Taking into account that many catalytic oxidation reactions liberate significant amounts of heat, temperatures above $1000^{\circ} \mathrm{C}$ can result. For methane oxidation on $\mathrm{Pt}$, the reactor has been successfully operated at temperatures up to $1300^{\circ} \mathrm{C}$.

As reacting gas mixtures containing fuel and oxidant under pressure can explode, a number of safety measures have been taken in designing and operating the reactor. In the first place, feeding of potentially explosive mixtures to the reactor can be avoided by providing upper and lower limits to the mass flow controllers which are outside the flammability limits of the gas mixture. Second, the reactor is equipped with a $1 / 2$ inch burst disk rated to a burst pressure of 45 bar being therefore the highest possible reactor pressure. In case of an explosion, the burst disk breaks and releases the pressure instantaneously. In addition to the burst disk, the reactor itself functions like a pressure relief valve, as number and strength of the springs between base and cover plate determine the leak pressure of the system. Depending on the application and the target pressure the spring load can be adjusted to a value slightly higher than the target pressure. To protect the operator in case of a bursting reactor tube, the ceramic split furnace surrounding the reactor tube is enclosed in a metal housing. Additionally, the entire reactor is shielded by a safety screen (not shown in Fig. 2).

\subsection{Measurement of gas species profile}

For measurement of high resolution gas species profiles a thin quartz capillary (outer diameter $=700 \mu \mathrm{m}$, inner diameter $=530 \mu \mathrm{m}$ ) runs through the center of the quartz tube and the catalyst bed. The latter can be of various shape. The sampling capillary possesses a small side sampling orifice with a diameter of about $50 \mu \mathrm{m}$ located at such a distance from the upper, closed end of the capillary that no open channel is left behind if the sampling orifice is moved to the lowest sampling point in the catalyst bed. Keeping the channel filled by the capillary is mandatory to avoid gas bypassing. The lower open end of the sampling capillary is connected to a microvolume stainless steel cross which in turn is connected to a stainless steel holder.
The stainless steel holder is mounted to a rotary stage and the rotary stage is mounted to a linear stage. With this arrangement it is possible to move the sampling capillary with $\mu \mathrm{m}$ resolution up and down and to rotate it. Rotating the capillary is important because some catalyst geometries (e.g., reticulated foams) can have irregular flow patterns and high quality spatial profile measurements will require averaging at different scan lines. To seal the capillary against the outside but still allow movement with minimum force, the capillary runs through a grease pit located between two stainless steel liners which have a slightly larger diameter than the capillary. When the capillary is inserted into these liners its outer surface picks up a thin grease layer. The annular gap between the capillary and the steel liners is narrow enough that even maximum reactor operation pressure (45 bar) is not sufficient to squeeze the high viscous grease through this annular gap. On the other hand, the grease allows slow movement of the capillary with minimum force as the pressure difference exerts only small forces.

Gas species sampling is accomplished by means of a transfer capillary connecting the microvolume stainless steel cross with a mass spectrometer. The transfer capillary is evacuated by means of a membrane pump to allow for rapid gas transport and avoid blocking by condensation of condensable species (e.g., water). Typically a flow of around $5 \mathrm{~cm}^{3} / \mathrm{min}$ is sampled through the sampling orifice.

\subsection{Measurement of gas and surface tempera- ture profiles}

To measure spatially resolved gas and surface temperature profiles, a thermocouple or a pyrometer fiber can be inserted in the sampling capillary, respectively. If the fiber tip or the thermocouple tip are aligned with the orifice position, the measured temperature can be assigned to the respective species composition measured at a certain point in the catalyst bed. This lifts the requirement of isothermicity in kinetic measurements, as the differential reaction rate measured at a particular point in the catalyst bed can be assigned to the catalyst temperature at this point. If a thermocouple is used, thermal contact exists between the sampled gases and the thermocouple tip but not between the thermocouple tip and the catalyst bed. Therefore, the thermocouple measurement is strongly biased to the real gas temperature as was shown in Ref. 3. If a pyrometer fiber is used, thermal radiation emitted from the catalyst surface can be collected and transformed into a surface temperature using a pyrometer. A two wavelength pyrometer should be used as the surface emissivity might change along the scan line.

Different temperature profiles measured by thermocouple and pyrometer fiber indicate heat transport limitations which are in most cases also indicative for external mass transport limitations due to similar transport mechanisms. Heat and mass transport limitations do often occur 

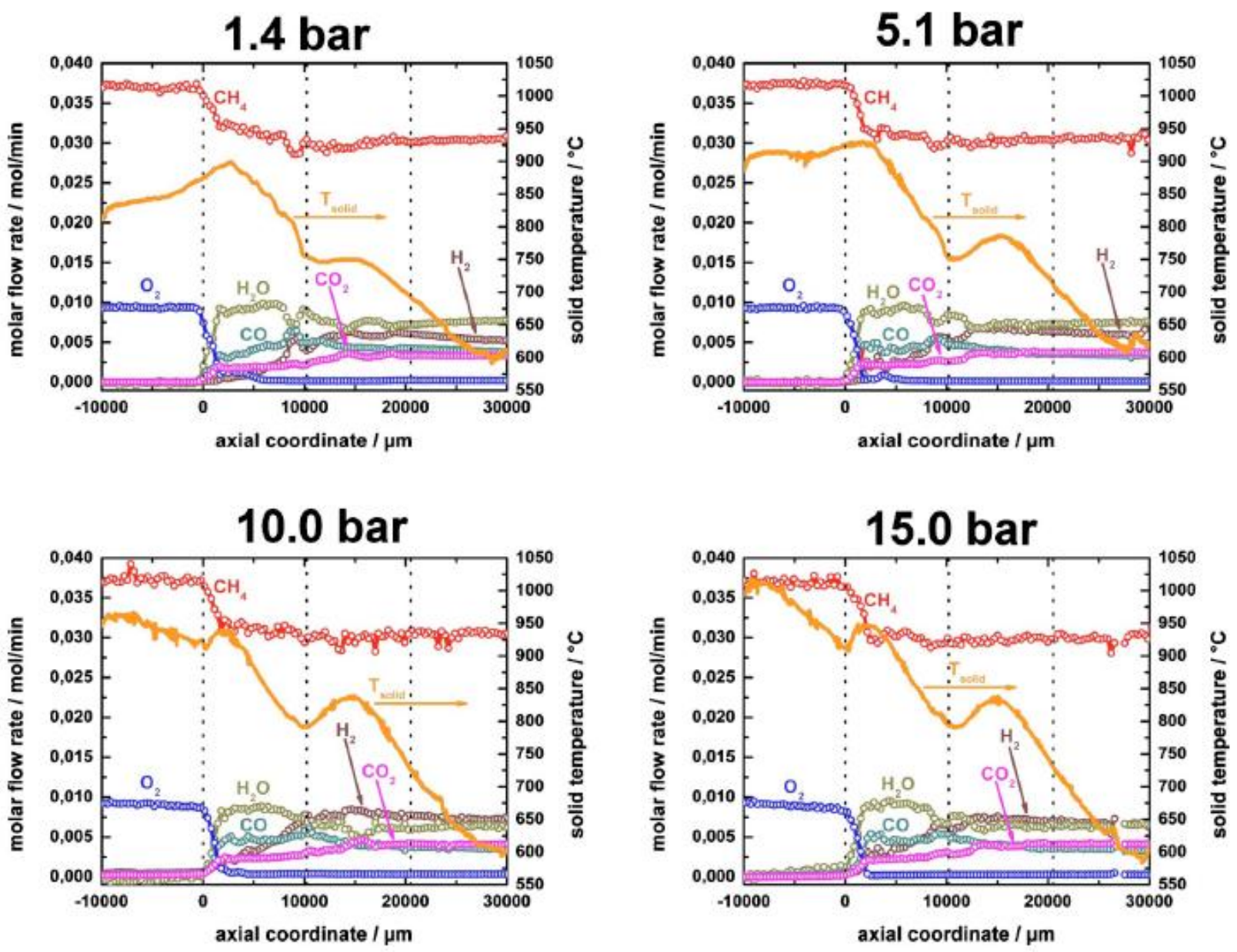

Fig. 3: Spatial profile measurements for methane oxidation on $0.6 \mathrm{wt} \% \mathrm{Pt}$ coated $45 \mathrm{ppi} \alpha-\mathrm{Al}_{2} \mathrm{O}_{3}$ foam catalysts. Gas flow: $911 \mathrm{ml} \mathrm{min}^{-1} \mathrm{CH}_{4}$, $228 \mathrm{ml} \mathrm{min}^{-1} \mathrm{O}_{2}, 858 \mathrm{ml} \mathrm{min}^{-1}$ Ar. $\mathrm{C} / \mathrm{O}=2.0$. Autothermal operation. Front heat shield $-10000 \mu \mathrm{m} \rightarrow 0 \mu \mathrm{m}$, catalyst section $0 \mu \mathrm{m} \rightarrow 10240$ $\mu \mathrm{m}$ (Pt foam 1) and $10240 \mu \mathrm{m} \rightarrow 20460 \mu \mathrm{m}$ (Pt foam 2), back heat shield $20460 \mu \mathrm{m} \rightarrow 30000 \mu \mathrm{m}$.

in high temperature catalytic reactions as chemical reactions at the catalyst surface are very fast. For example, in methane catalytic partial oxidation on Rh coated foam catalysts, temperature gradients of several hundred degree Centigrade have been measured at the entrance of the foam catalyst and both, experimental data [6] and numerical simulations [3] indicate strong oxygen transport limitation at the catalyst entrance.

\section{Application Examples}

\subsection{Methane oxidation on Pt coated $\alpha-\mathrm{Al}_{2} \mathrm{O}_{3}$ foam catalysts from 1.4 to 15 bar}

The reactor described in Sec. 2 was used to study methane oxidation on autothermally operated $\mathrm{Pt}$ coated $\alpha-\mathrm{Al}_{2} \mathrm{O}_{3}$ foam catalysts at pressures from 1.4 to $15 \mathrm{bar}$. The pressure was varied to investigate whether gas phase reactions proceed in parallel to catalytic reactions and whether transport limitations occur. For this application the catalyst bed was formed by two $10 \mathrm{~mm}$ long $\alpha-\mathrm{Al}_{2} \mathrm{O}_{3}$ foam cata- lysts [45 pores per linear inch (ppi)] coated by $0.6 \mathrm{wt} \% \mathrm{Pt}$ using the microwave assisted combustion synthesis $\operatorname{method}^{7}$ and sandwiched between two uncoated $10 \mathrm{~mm}$ long 45 ppi foams which served as heat shields. The $1 \mathrm{~mm}$ channels for the sampling capillary were drilled before coating with Pt. The feed gas mixture consisted of $\mathrm{CH}_{4} / \mathrm{O}_{2} / \mathrm{Ar}\left(911 / 228 / 858 \mathrm{ml} \mathrm{min}^{-1}\right.$ at STP). To assign a catalyst temperature to each gas species composition, the surface temperature was measured by means of a pyrometer fiber inserted in the capillary as described in Sec. 2D. Spatial reactor profiles were measured for total pressures of 1.4, 5.1, 10, and 15 bar. All data are summarized in Fig. 3.

Even though a detailed discussion of the experimental results is beyond the scope of this paper which focuses on the description of the reactor, the profiles reveal immediately interesting details of the methane oxidation mechanism. It can be seen that there exists a short zone behind the catalyst entrance where $\mathrm{CH}_{4}$ and $\mathrm{O}_{2}$ are rapidly converted. The chemistry in this entrance zone which extends from 0 $2400 \mu \mathrm{m}$ can be described by Eq. (1) with $x$ taking values between $0 \leq x \leq 2$ and $y$ taking values between $0 \leq y \leq 1$. 


$$
\begin{aligned}
\mathrm{CH}_{4}+ & \left(2-\frac{x}{2}-\frac{y}{2}\right) \mathrm{O}_{2} \\
\rightarrow & x \mathrm{H}_{2}+y \mathrm{CO}+(2-x) \mathrm{H}_{2} \mathrm{O} \\
& +(1-y) \mathrm{CO}_{2}, \quad \Delta H_{r}^{\ominus}=f(x, y) .
\end{aligned}
$$

Noncatalytic methane total oxidation occurs for pressures $p \geq 10$ bar as can be seen from Fig. 3 (10 and 15 bar measurements) where a slight conversion of $\mathrm{O}_{2}$ is already observed in the front heat shield accompanied by liberation of heat due to the high combustion enthalpy of methane $\left(\Delta H r \ominus=-803 \mathrm{~kJ} \mathrm{~mol}^{-1}\right)$. This explains why at 10 and 15 bar the temperature in the front heat shield is higher than in the catalyst section.

Upon complete $\mathrm{O}_{2}$ conversion, secondary reactions such as steam reforming [Eq. (2)] and watergas shift [Eq. (3)] are taking place until the mixture leaves the catalyst (2400-20460 $\mu \mathrm{m})$.

$$
\begin{aligned}
& \mathrm{CH}_{4}+\mathrm{H}_{2} \mathrm{O} \rightarrow \mathrm{CO}+3 \mathrm{H}_{2}, \quad \Delta H_{r}^{\ominus}=+206 \mathrm{~kJ} \mathrm{~mol}^{-1}, \\
& \mathrm{CO}+\mathrm{H}_{2} \mathrm{O} \rightarrow \mathrm{CO}_{2}+\mathrm{H}_{2}, \quad \Delta H_{r}^{\ominus}=-41 \mathrm{~kJ} \mathrm{~mol}^{-1} .
\end{aligned}
$$

As shown in Fig. 4 the $\mathrm{O}_{2}$ profiles fall on top of each other in the catalytic zone and are highly linear. As can be deduced from an $\mathrm{O}_{2}$ mass balance, the strict linearity observed in the oxidation zone between 0 and $2000 \mu \mathrm{m}$ is in disagreement with $\mathrm{O}_{2}$ film transport limitation as this should lead to an exponentially decreasing $\mathrm{O}_{2}$ flow rate in this section as outlined in Eq. (4).

$$
\begin{aligned}
\rho \cdot u \cdot \frac{d Y_{\mathrm{O}_{2}}^{\text {bulk }}}{d z} & =\frac{S}{V} \cdot k_{\mathrm{O}_{2}}^{m} \cdot \rho \cdot\left(Y_{\mathrm{O}_{2}}^{\text {surface }}-Y_{\mathrm{O}_{2}}^{\text {bulk }}\right) \Rightarrow F_{\mathrm{O}_{2}}^{z} \\
& =F_{\mathrm{O}_{2}}^{0} \cdot \exp \left(-\frac{S}{V} \frac{k_{\mathrm{O}_{2}}^{m}}{u} z\right) .
\end{aligned}
$$

In Eq. (4), $\rho$ denotes the gas density in $\mathrm{kg} \mathrm{m}^{-3}, u$ the linear gas velocity in $\mathrm{m} / \mathrm{s}$ (which can be considered constant in this short section), $\mathrm{YO}_{2}$ bulk and $\mathrm{YO}_{2}$ surface the $\mathrm{O}_{2}$ mass fraction in the bulk and at the Pt surface, respectively $\left(Y \mathrm{O}_{2}\right.$ surface $=0$ in case of full transport limitation $), S / V$ the catalyst surface to free gas volume ratio in $\mathrm{m}^{-1}, \mathrm{kO}_{2} m$ the $\mathrm{O}_{2}$ film mass transport coefficient in $\mathrm{m} / \mathrm{s}$, and $\mathrm{FO}_{2} z$ the $\mathrm{O}_{2}$ molar flow rate in $\mathrm{mol} \mathrm{min}^{-1}$ at position $z$, the quantity that is actually measured in Fig. 4.

The observed strict linearity is rather in agreement with a constant $\mathrm{O}_{2}$ consumption rate $r$ in $\mathrm{mol} \mathrm{m}^{-2} \mathrm{~s}^{-1}$ at the Pt surface as can be derived from the corresponding $\mathrm{O}_{2}$ mass balance [Eq. (5)]

$$
\begin{aligned}
\rho \cdot u \cdot \frac{d Y_{\mathrm{O}_{2}}}{d z} & =-r \cdot \frac{S}{V} \cdot M_{\mathrm{O}_{2}} \Rightarrow F_{\mathrm{O}_{2}}^{z} \\
& =F_{\mathrm{O}_{2}}^{0}-r \cdot \frac{S}{V} \cdot \frac{F_{\text {total }}^{0} \cdot \bar{M}^{0}}{\rho \cdot u} \cdot z .
\end{aligned}
$$

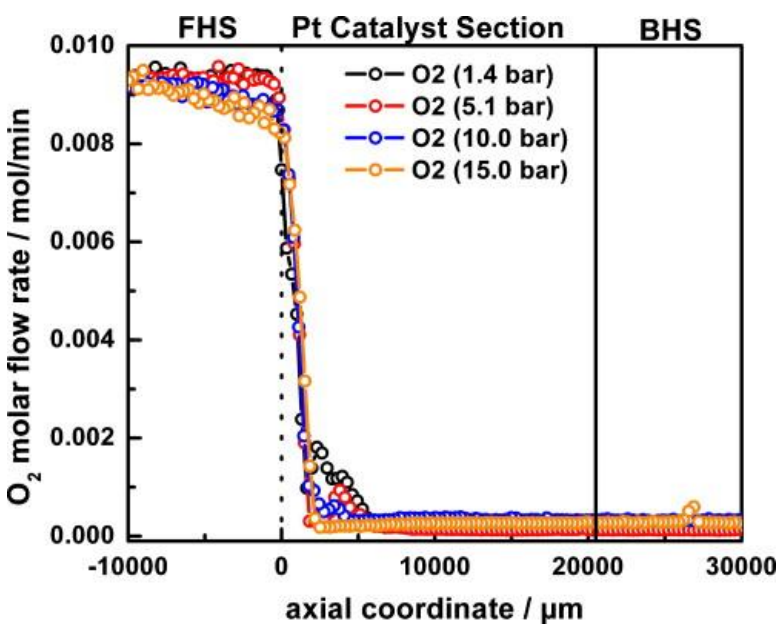

Fig.4 : Oxygen profiles from Fig. 3 superimposed. Linearity and pressure independence indicate zeroth order kinetics in the oxidation zone.

Equation (5), in which $M_{\mathrm{O} 2}$ and $\square^{0}$ denote the molar mass of oxygen and the mean molar mass of the gas mixture at the position $z=0$, is in qualitative agreement with the measured linear decrease in $\mathrm{FO}_{2} z$ between 0 and 2000 $\mu \mathrm{m}$ independent of reactor pressure. The chemical interpretation of the observed zeroth order kinetics could be a blockage of most active Pt sites by one dominant surface species. In situ Raman measurements which will be discussed in a forthcoming paper indicate, that the Pt surface is under above mentioned reaction conditions nearly entirely covered by carbon deposits.

\subsection{Methane oxidative coupling on $\mathrm{Li} / \mathrm{MgO}$ coated $\mathrm{\alpha}-\mathrm{Al}_{2} \mathrm{O}_{3}$ foam catalysts at atmospheric pressure}

The oxidative coupling of methane [OCM, Eq. (6)] to $\mathrm{C}_{2}$ hydrocarbons $\left(\mathrm{C}_{2} \mathrm{H}_{6}, \mathrm{C}_{2} \mathrm{H}_{4}\right.$, and $\left.\mathrm{C}_{2} \mathrm{H}_{2}\right)$ on Li doped $\mathrm{MgO}$ was chosen as second example to demonstrate how important mechanistic insight can be obtained from spatial reactor profile measurements.

$$
2 \mathrm{CH}_{4}+\mathrm{O}_{2} \rightarrow \mathrm{C}_{2} \mathrm{H}_{4}+2 \mathrm{H}_{2} \mathrm{O}, \quad \Delta H_{r}^{\ominus}=-370 \mathrm{~kJ} \mathrm{~mol}^{-1} .
$$

The OCM reaction is debated in the literature in terms of a so called "heterogeneous-homogeneous mechanism" meaning that the $\mathrm{Li} / \mathrm{MgO}$ catalyst produces $\mathrm{CH}_{3}$ radicals which desorb into the gas phase and couple there to $\mathrm{CH}_{3}-\mathrm{CH}_{3}$ which is further dehydrogenated to $\mathrm{CH}_{2}=$ $\mathrm{CH}_{2}$.[8] Methane oxidative coupling, even though highly attractive from an industrial point of view, is still at the research stage as one-pass yields higher than about 25\% could not yet been achieved. The reason for this virtual bound is still unclear. 


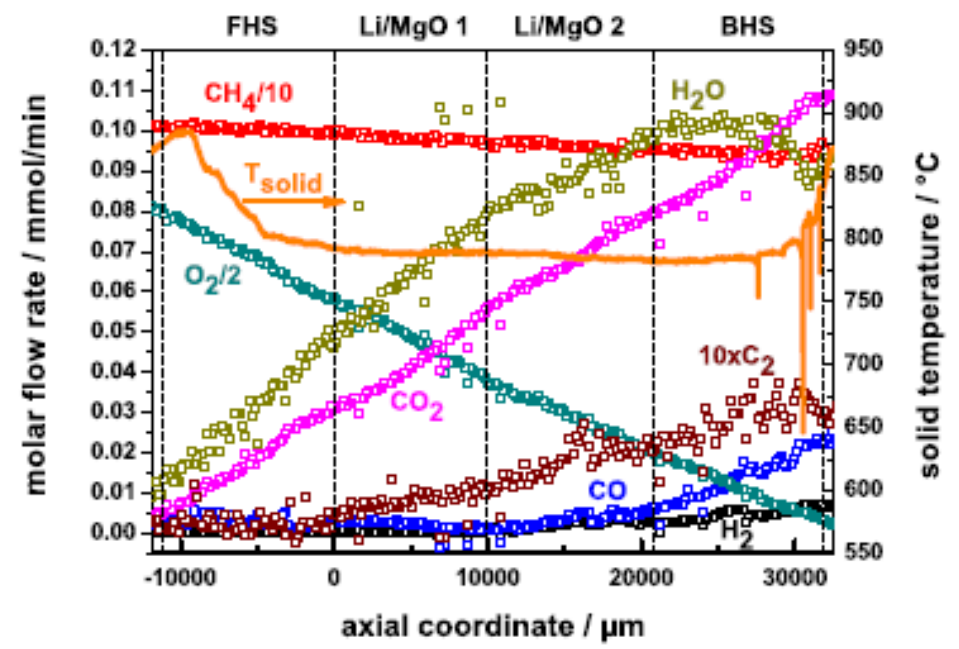

Fig. 5: Spatial profile measurements for methane oxidative coupling on $\mathrm{Li} / \mathrm{MgO}$. Catalyst section formed by two 0.8 wt $\%$ Li/MgO coated $\alpha-\mathrm{Al}_{2} \mathrm{O}_{3}$ foams. Gas flow $\mathrm{CH}_{4} / \mathrm{O}_{2} / \mathrm{Ar}=25.6 / 6.4 / 8.0 \mathrm{ml} \mathrm{min}{ }^{-1}$. Reactor temperature by external heating $780{ }^{\circ} \mathrm{C}$. Atmospheric pressure.

Profile measurements were conducted in an analogous manner as described in Sec. 3A with the only differences that two $10 \mathrm{~mm}$ long $0.8 \mathrm{wt} \% \mathrm{Li} / \mathrm{MgO}$ coated $45 \mathrm{ppi}$ $\alpha-\mathrm{Al}_{2} \mathrm{O}_{3}$ foams served as catalyst section, much lower flow rates were used $\left(\mathrm{CH}_{4} / \mathrm{O}_{2} / \mathrm{Ar}=25.6 / 6.4 / 8.0 \mathrm{ml} \mathrm{min}{ }^{-1}\right.$ at STP) and that the reactor was heated to about $780^{\circ} \mathrm{C}$. Very low total flow rates had to be used as methane oxidation on $\mathrm{Li} / \mathrm{MgO}$ is much slower than on Pt and external heating was necessary as the reaction, due to its low rate, does not produce sufficient heat for autothermal operation. The spatial profiles are depicted in Fig. 5. Again, the pyrometer fiber was used as temperature probe to measure the catalyst temperature.

The pyrometer temperature profile shows that the reactor is very isothermal in the catalytic section $\left(788 \pm 2{ }^{\circ} \mathrm{C}\right)$. The increase in the temperature curve toward the ends of both heat shields is a measurement artifact as radiation from the much hotter heating coils of the oven is reflected by the mounting clamps into the heat shields. Longer heat shields could eliminate this problem.

The species profiles reveal a number of interesting details. It can be seen that methane is lost with constant rate by total oxidation to $\mathrm{CO}_{2}$ and $\mathrm{H}_{2} \mathrm{O}$. This total oxidation occurs either in the gas phase as it is not restricted to the catalyst section or at the $\alpha-\mathrm{Al}_{2} \mathrm{O}_{3}$ support. $\mathrm{C}_{2}$ coupling products (at $780{ }^{\circ} \mathrm{C}$ only $\mathrm{C}_{2} \mathrm{H}_{6}+\mathrm{C}_{2} \mathrm{H}_{4}$ ) are not formed before the reactants enter the catalyst section indicating that precatalytic $\mathrm{C}_{2}$ formation does not occur. Even though only small amounts of $\mathrm{C}_{2}$ are formed the profile shows clearly that $\mathrm{C}_{2}$ species are formed with a constant rate and that the formation continues behind the catalyst section in the back heat shield. This could be due to loose catalyst material that has been transported by the gas flow to the back heat shield. However, as the gas flow is extremely slow and directed against gravity this explanation is not very likely. The postcatalytic $\mathrm{C}_{2}$ production could also indicate formation of $\mathrm{C}_{2}$ products in the gas phase triggered by the catalyst in line with a "heterogeneous-homogeneous" mechan- mechanism. $\mathrm{CO}$ seems to be a secondary product as its formation starts quite late in the catalyst section. Virtually no hydrogen is formed at all.

\section{Summary and Conclusions}

A novel reactor allowing simultaneous measurements of spatially resolved species and temperature profiles in heterogeneous catalytic reactions under industrially relevant conditions is presented. The principle of spatial profile measurements is based on a movable sampling capillary for species analysis which houses either a thermocouple for gas temperature measurements or a pyrometer fiber for catalyst temperature measurements. The maximum operation pressure and the maximum operation temperature of the reactor are 45 bar and $1300{ }^{\circ} \mathrm{C}$, respectively. For operation under pressure, the reactor tube is sealed by form fitting into mounting clamps which are pressed together using a variable number of springs. The spring load can be adjusted to match the target pressure allowing the reactor to open and release pressure if the target pressure is exceeded. In case of an explosion, a rupture disk ensures instantaneous pressure release. Application examples are given for high temperature methane oxidation on Pt coated foam catalysts and methane oxidative coupling on $\mathrm{Li} / \mathrm{MgO}$ coated foam catalysts. Reaction pathways and kinetic implications are briefly discussed.

\section{Acknowledgements}

The authors thank the German Research Foundation for funding the Emmy-Noether-Junior-Research-Group "High Temperature Catalysis." Further support was provided by the German Federal Ministry of Education and Research within the framework of the Excellence Cluster "Unifying Concepts in Catalysis." 


\section{References}

[1] J. M. Berty, Chem. Eng. Prog. 70, 78 (1974)

[2] D. Farrusseng, Surf. Sci. Rep. 63, 487 (2008).

[3] D. Dalle Nogare, N. J. Degenstein, R. Horn, P. Canu and L. D. Schmidt, J. Catal. 258, 131(2008).

[4] R. Horn, K. A. Williams, N. J. Degenstein and L. D. Schmidt, J. Catal. 242, 92 (2006).

[6] R. Horn, K. A. Williams, N. J. Degenstein, A. Bitsch-Larsen, D. Dalle-Nogare, S. A. Tupy and L. D. Schmidt, J. Catal. 249, 380 (2007).

[7] U. Zavyalova, F. Girgsdies, O. Korup, R. Horn and R. Schloegl, J. Phys. Chem. C. 113, 17493 (2009).

[8] J. H. Lunsford, Angew. Chem. Int. Ed. Engl. 34, 970 (1995).

[5] R. Horn, N. J. Degenstein, K. A. Williams and L. D. Schmidt, Catal. Lett. 110, 169 (2006). 